\title{
Multiscale effects of habitat and surrounding matrices on waterbird diversity in the Yangtze River Floodplain
}

\author{
Boyu Gao $\cdot$ Peng Gong $\cdot$ Wenyuan Zhang $\cdot$ Jun Yang $\cdot$ Yali Si $\mathbb{D}$
}

Received: 21 October 2019/Revised: 21 September 2020/ Accepted: 22 September 2020/Published online: 29 September 2020

(C) The Author(s) 2020

\begin{abstract}
Context With the expansion in urbanization, understanding how biodiversity responds to the altered landscape becomes a major concern. Most studies focus on habitat effects on biodiversity, yet much less attention has been paid to surrounding landscape matrices and their joint effects.

Objective We investigated how habitat and landscape matrices affect waterbird diversity across scales in the Yangtze River Floodplain, a typical area with high biodiversity and severe human-wildlife conflict.
\end{abstract}

Electronic supplementary material The online version of this article (https://doi.org/10.1007/s10980-020-01131-4) contains supplementary material, which is available to authorized users.

B. Gao $\cdot$ P. Gong $\cdot$ J. Yang $\cdot$ Y. Si

Ministry of Education Key Laboratory for Earth System

Modelling, Department of Earth System Science,

Tsinghua University, Beijing, China

\section{W. Zhang}

Department of Zoology, University of Oxford, Oxford, UK

\section{Y. Si}

Institute of Environmental Sciences, Leiden University, Leiden, The Netherlands

\section{Y. Si $(\bowtie)$}

Department of Earth System Science, Tsinghua University, Qinghuayuan 1, Beijing 100084, China

e-mail: y.si@cml.leidenuniv.nl
Methods The compositional and structural features of the landscape were calculated at fine and coarse scales. The ordinary least squares regression model was adopted, following a test showing no significant spatial autocorrelation in the spatial lag and spatial error models, to estimate the relationship between landscape metrics and waterbird diversity.

Results Well-connected grassland and shrub surrounded by isolated and regular-shaped developed area maintained higher waterbird diversity at fine scales. Regular-shaped developed area and cropland, irregular-shaped forest, and aggregated distribution of wetland and shrub positively affected waterbird diversity at coarse scales.

Conclusions Habitat and landscape matrices jointly affected waterbird diversity. Regular-shaped developed area facilitated higher waterbird diversity and showed the most pronounced effect at coarse scales. The conservation efforts should not only focus on habitat quality and capacity, but also habitat connectivity and complexity when formulating development plans. We suggest planners minimize the expansion of the developed area into critical habitats and leave buffers to maintain habitat connectivity and shape complexity to reduce the disturbance to birds. Our findings provide important insights and practical measures to protect biodiversity in human-dominated landscapes.

Keywords Biodiversity conservation - Waterbird habitat . The landscape matrix $\cdot$ Landscape 
connectivity $\cdot$ Shape complexity $\cdot$ Urban and rural planning

\section{Introduction}

Anthropogenic landscape modification is the major cause of biodiversity loss (Fischer and Lindenmayer 2007; Guadagnin and Maltchik 2007), and is one of the most pressing challenges for ecologists and conservation biologists. Globally, urban and rural areas are developing rapidly (Andrade et al. 2018), vastly altering the landscape composition and structure of wildlife habitats and their surroundings. However, the influence on urban development is not ubiquitous for biodiversity and is instead dependent on landscape composition and configuration at local and regional scales (Andrade et al. 2018). Wetlands, as important biodiversity hotspots, maintain high biodiversity and biological productivity (Forbes 2000; Dudgeon et al. 2006; Green et al. 2017), and offer habitat for many threatened species (Green 1996; Dudgeon et al. 2006). Though some wetlands are under protection, human activities remain a threat to wetland biodiversity, resulting in degraded ecosystem services (Green 1996; Nassauer 2004; Galewski et al. 2011; Martínez-Abraín et al. 2016). For example, due to dryland development, such as for agriculture and urban construction, large numbers of natural wetlands are deteriorated (Nilsson et al. 2005; Niu et al. 2012). Waterbirds (e.g. swans, geese, ducks, and herons), that rely on wetland habitats are sensitive to the environmental change and are often regarded as important indicators of ecosystem health (Ogden et al. 2014). Nevertheless, populations of such important bird groups are declining globally, which calls for new strategies for conservation of both waterbirds and wetlands (Amano et al. 2018).

Habitat characteristics influence bird distribution, abundance and diversity (Paracuellos and Telleria 2004; Beatty et al. 2014). For example, Zhang et al. (2018) found that waterfowl prefer areas with wellconnected waterbodies and wetlands. Neotropical migrants are more abundant in landscapes with a greater proportion of forest and wetland (Flather and Sauer 1996). Shorebird abundance is positively affected by wetland area and number of wetlands (Webb et al. 2010). Moreover, greater habitat patch size, core area, edge and connectivity positively influence bird diversity (Wu et al. 2011). Nevertheless, the suitability of an area for birds depends on the condition of both habitat and the surrounding landscape matrix (Saab 1999; Guadagnin and Maltchik 2007; Elphick 2008; Perez-Garcia et al. 2014). For example, Morimoto et al. (2006) found that two woodland bird species prefer woodlands surrounded by agricultural areas over those surrounded by urban areas. Francesiaz et al. (2017) found that gulls prefer ponds surrounded by meadow and fallow land rather than woodland. Dallimer et al. (2010) found that the size of urban area and the amount of grassland patches affect the richness of moorland bird species in northern England. Nevertheless, studies investigating the effect of the landscape matrix have mainly considered the distance of the landscape matrix to habitats (Debinski et al. 2001; Summers et al. 2011), or the size and amount of the matrix (Guadagnin et al. 2009; Dallimer et al. 2010; Egerer et al. 2016). Thus, the effect of detailed characters (such as shape complexity and connectivity) of the surrounding landscape matrix on bird diversity are largely unknown.

Landscape metrics are frequently used to evaluate landscape pattern change (Riitters et al. 1995; Lausch and Herzog 2002), habitat characters (Mcalpine and Eyre 2002; Bailey et al. 2007), and linked to biodiversity (Bailey et al. 2007; Walz 2011; García-Llamas et al. 2018). Landscape metrics can be used to assess biodiversity at a higher and integrated level (Walz 2011) as higher environmental diversity leads to higher species diversity (Ricotta et al. 2003). These metrics can also capture biotic processes, such as immigration (Honnay et al. 2003) and biotic interactions (Simmonds et al. 2019). Numerous metrics have been proposed to quantify landscape composition, configuration and connectivity (Šímová and Gdulová 2012; Sklenicka et al. 2014), covering the patch size, dominance, shape complexity, fragmentation, connectivity, landscape diversity, contagion and aggregation (Mcgarigal and Marks 1995). We used these metrics to quantify the character of habitat and surrounding landscape matrices to investigate their effects on waterbird diversity.

Moreover, birds respond to their environment differently at different spatial scales and hence different conservation plans are needed across scales (Wiens 1989; Zhang et al. 2018). The surrounding environment tend to play a more important role at coarser scales as birds avoid areas highly disturbed by human activities 
(Si et al. 2020), which often are a large component of landscape matrices (Herbert et al. 2018; Souza et al. 2019). However, the understanding of how landscape matrices affect bird diversity across spatial scales, in particular at coarse scales, is rather limited. Previous studies (Chan et al. 2007; Guadagnin and Maltchik 2007; De Camargo et al. 2018) investigating the effect of habitat and the surroundings on bird communities mainly focus on fine scales (500 m to $10 \mathrm{~km}$ ). Considering that the maximum mean foraging flight distances of ducks and geese is $32.5 \mathrm{~km}$ (Johnson et al. 2014) and is generally $<50 \mathrm{~km}$ (Ackerman et al. 2006; Si et al. 2011; Johnson et al. 2014), we chose the spatial scale $>10 \mathrm{~km}$ and $<50 \mathrm{~km}$ as the coarse scales to further investigate how the landscape features influence waterbird diversity.

This study investigates how habitat and landscape matrices affect waterbird diversity in the Yangtze River Floodplain across spatial scales using spatial and ordinary least squares regression models. We hypothesize that (1) habitat and landscape matrices jointly affect waterbird diversity, and (2) the effect of landscape matrices outweighs that of habitats at coarse scales.

\section{Methods}

Study area

The Yangtze River Floodplain (thereafter YRF, $28.3^{\circ}-$ $33.6^{\circ} \mathrm{N}, 112.2^{\circ}-122.5^{\circ} \mathrm{E}$; Fig. 1) is located in the humid subtropical climate zone. The annual average temperature ranges from $14{ }^{\circ} \mathrm{C}$ to $18{ }^{\circ} \mathrm{C}$ and average annual rainfall is from $1,000 \mathrm{~mm}$ to $1,400 \mathrm{~mm}$ (Xie et al. 2017; Wei et al. 2019). In this region, 11 Ramsar sites (wetlands of international importance, designated under the Ramsar Convention; http://www.ramsar. org) and 31 wetlands (including 10 national and 21 provincial-level wetlands) are designated as protected areas. A seasonal flood-drought cycle results in high water levels in spring and summer, followed by low water level in autumn and winter (Wei et al. 2019). Flooding brings nutrients and organic matter into the wetlands, during drought cycles as water levels decline, the large number of wetlands provide abundant feeding areas for waterbirds (Xu et al. 2017; Wei et al. 2019). YRF, as an important wintering area for local and migratory birds along the East Asian-
Australasian Flyway, is composed of variable types of wetlands such as flooded wetlands, inland marshes, swamps and mudflats.

YRF is one of the Global 200 priority ecoregions for conservation identified by the World Wide Fund for Nature (Olson et al. 1998), and it provides habitat for about one million wintering waterbirds (Wang et al. 2017). Meanwhile, YRF, flowing through Shanghai and Hunan, Hubei, Jiangxi, Anhui and Jiangsu provinces, plays an important role in Chinese economy, agriculture and industry (Hollert 2013), support 29\% of China's population (about 400 million) and produces more than $40 \%$ of the national GDP (Wang et al. 2017). Intensive human activities (such as agriculture, urbanization, land reclamation and conversion, etc.) in this region makes YRF one of the most critical and endangered ecoregions in the world (Olson and Dinerstein 2002). Thus, YRF is an appropriate region to explore how species diversity responds to the altered landscape patterns. There is an urgent need to generate sustainable development plans to solve the conflicts between economic development and biodiversity conservation in YRF.

Waterbird survey data

We obtained the waterbird survey data for 101 sites along YRF from The World Wide Fund for Nature (WWF; survey was carried out from 9 to 13 January 2011). This time of year was chosen because the distribution of wintering birds is relatively stable and concentrated. The survey sites where bird congregate were identified based on expert knowledge. Various methods were used to approach the survey sites. The survey team usually drove as close as possible and then walked on foot. Birds were counted by experienced field ornithologists from early morning and through the day using telescope, in at least two locations of one surveyed wetland. A total of 136 waterbird species were recorded during the survey. In some regions, only data at the county level was summarized and the counts corresponding to specific wetlands were not available. For example, the count in the Xingzi County (Jiangxi Province, China) is the sum of three wetlands. We excluded these records and only used data for sites with accurate geographical locations of a specific wetland and corresponding bird counts for further analyses (Fig. 1). 


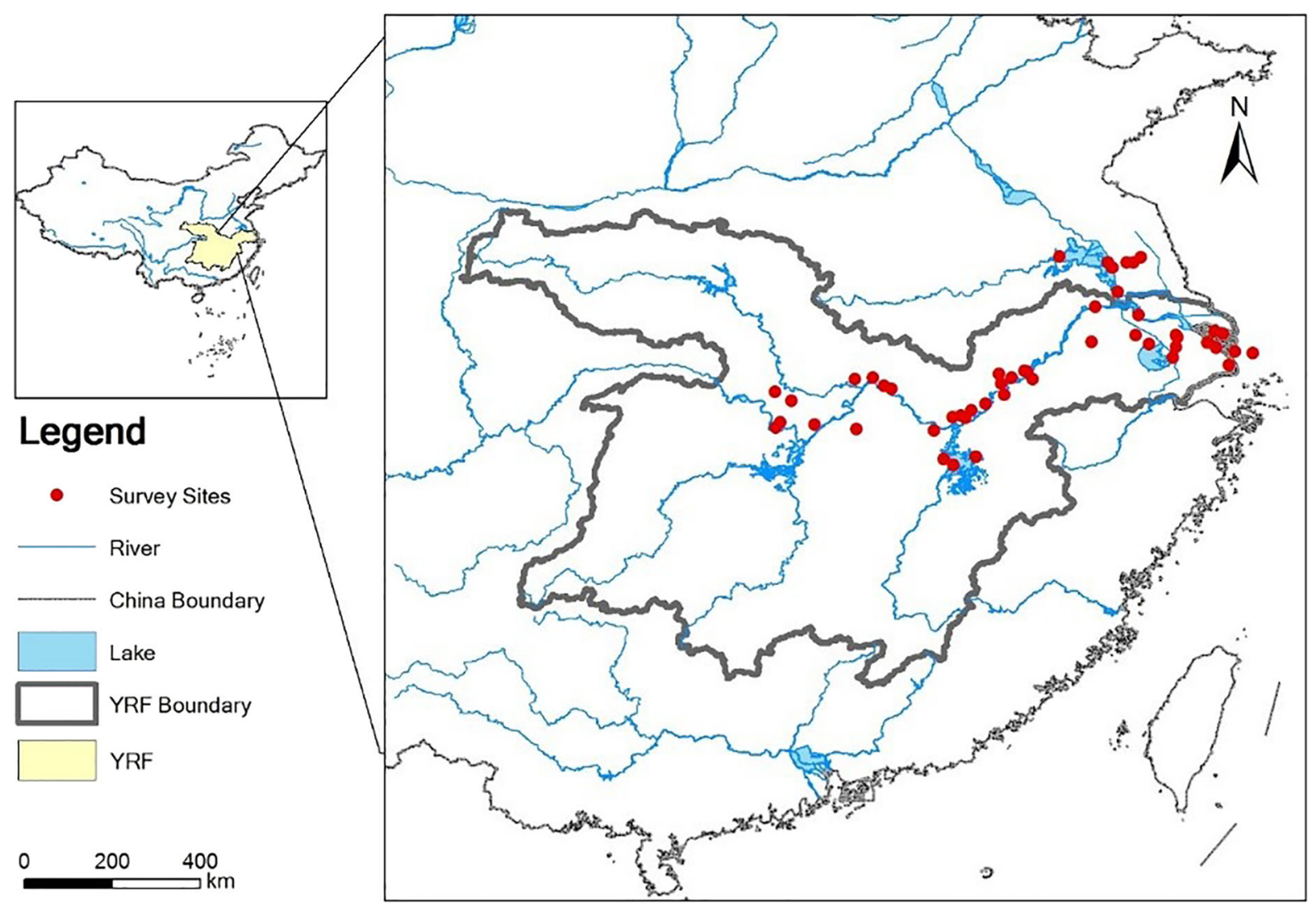

Fig. 1 Location of the Yangtze River Floodplain (YRF) and waterbird survey sites (red dots)

\section{Land cover map}

We used the aggregation land cover map of the finer resolution observation and monitoring of global land cover in 2010 (FROM-GLC-agg; http://data.ess. tsinghua.edu.cn; Yu et al. 2014) to calculate landscape metrics. According to the classification scheme of $\mathrm{Li}$ et al. (2016), we reclassified land cover map into nine types: cropland, forest, grassland, shrub, wetland, water, developed area and bareland. As wetlands are difficult to characterize by automatic classification (Yu et al. 2016), we replaced the water and wetland classifications in the FROM-GLC map with a 2008 wetland map generated based on human interpretation and multi-temporal imagery (Niu et al. 2012). Specifically, with the wetland map, 'water' is composed of recreational waters, artificial channels and fish farms, and 'wetland' includes shallow beaches, coastal marshes, estuary deltas, flooded wetlands and inland marshes. We then categorized land-use types into waterbird habitat (wetland, water, grassland, and shrub) and the surrounding landscape matrix (cropland, forest, bareland, and developed area). Grassland and shrub were included as habitat because grass is a potential food resource for some waterbirds and shrub could be used for resting or roosting. Cropland was classified as the landscape matrix due to a limited number of observed waterbird species in this land cover type (12/136 species).

\section{Waterbird diversity}

The Shannon-Wiener index has been frequently used to measure species diversity (Macarthur 1955; Lin et al. 2011; Dronova et al. 2016). It combine richness and evenness and can be used to compare the species diversity among different sites (Payne et al. 2005; Lin et al. 2011). The index (Hill 1973) is calculated for each site by Eq. (1):

$$
\mathrm{H}^{\prime}=-\sum_{i}^{s} P_{i} \ln P_{i}
$$


where $s$ is the total number of species and $P_{i}$ is the proportion of individuals of species $i$ to the total individuals of all species.

Landscape metrics at fine and coarse spatial scales

To quantify the habitat feature and landscape matrices, we generated circular buffers around the locations of sites at different spatial scales i.e., $5 \mathrm{~km}, 10 \mathrm{~km}$, $20 \mathrm{~km}, 25 \mathrm{~km}, 40 \mathrm{~km}$ and $50 \mathrm{~km}$, as the radii. We defined $5 \mathrm{~km}$ - and $10 \mathrm{~km}$-scale as the fine scales (Forcey et al. 2011; Morelli et al. 2013), and scales larger than $10 \mathrm{~km}$-scale as the coarse scales.

Landscape metrics were selected based on the lifehistory and ecological characteristics of waterbirds (Madsen 1985; Si et al. 2011; Li et al. 2017; Zhang et al. 2018). Table 1 lists the selected metrics covering multiple forms of patch size, dominance, shape complexity, fragmentation, connectivity, landscape diversity, contagion and aggregation (Mcgarigal and Marks 1995). For patch size and shape complexity, we also calculated their mean, minimum, maximum and standard deviation. Patch size includes patch area (PA) and patch core area (PCO), with a higher value indicating a larger patch. The core area represents the interior area of a patch after a user-specified edge buffer is eliminated. Smaller patches with greater shape complexity have a smaller PCO (Mcgarigal and Marks 1995; De Smith et al. 2007). Metrics for shape complexity include perimeter area ratio (PAR), shape index (SI) of each land cover type. Higher PAR and SI indicate greater shape complexity or greater deviation from regular geometry. Patch density (PD) and splitting index (SPI) (Green et al. 2017) represent the fragmentation level, while patch cohesion index (PCI) (Concepcion et al. 2016) indicates the connectivity level. Higher values of PD and SPI indicate more isolated patches, whereas higher PCI indicates more connected patches. Landscape Shannon index (LSHD) indicates the level of landscape diversity, with a higher value representing higher heterogeneity of patches in the landscape. Contagion index (CI) and aggregation index (AI; Li and Reynolds 1993) measure the extent of aggregation of patches for one particular land cover type. $\mathrm{CI}$ and $\mathrm{AI}$ increase if a landscape is dominated by large and well-connected patches. Landscape metrics were calculated in $\mathrm{R}$ 3.3.3 using the package 'SDMTools'. All metrics were standardized using z-score normalization transformation for the further analyses.

\section{Statistical analyses}

We first tested the influence of each landscape metric on waterbird diversity using univariate linear regression. Only significant metrics ( $\mathrm{p}$ value $<0.05$ ) were included (Forcey et al. 2011). A preselection was then carried out to exclude metrics with relatively high autocorrelation or high collinearity. Specifically, we used Moran's I to detect autocorrelation and metrics with a Moran's I larger than 0.5 or smaller than -0.5 were removed. We then use Variance Inflation Factors (VIF; Marquardt 1970) to diagnose collinearity. VIF measures the amount of multicollinearity in a set of multiple regression variables and tests the multiple correlation coefficient between one variable and the rest of variables. Specifically, we dropped the metric with relatively less impact (based on the result of the univariate linear regression), and repeated this process until VIFs of each variable were $<10$. Considering the potential spatial dependency among survey sites, we used both spatial regressions (the spatial lag model SLM and the spatial error model SEM) and the Ordinary Partial Least Squares (OLS) regression. The non-significant metrics were removed, and variables kept in the final model were considered as key landscape metrics.

Two spatial autoregressive models were used to detect the level of spatial autocorrelation. A matrix of spatial weights W was calculated based on Euclidean distances between survey sites. The one is the spatial lag model (SLM) that adds a lag term of the dependent variable y into the OLS model. This model explains the spatial interaction between survey sites based on their proximity, as given by Eq. (2):

$\mathrm{y}=\beta \mathrm{X}+\rho \mathrm{Wy}+\varepsilon$

where $\beta$ is the correlation coefficient of the independent variable $\mathrm{X}, \mathrm{W}$ is a spatial weights matrix indicating distance relationship between pairs of survey sites. $\rho$ is the coefficient of the spatially lagged variable $\mathrm{Wy}$ on the matrix of weight $\mathrm{W}$ applied to response values from spatial neighbors of each survey site, and $\varepsilon$ is the random error. 
Table 1 Summary of the landscape metrics used for investigating the effect of habitat and surrounding matrices on waterbird diversity

\begin{tabular}{|c|c|c|c|}
\hline Category & Landscape metrics & Abbreviation & Description \\
\hline \multirow[t]{2}{*}{ Patch size } & Patch area & PA & $\begin{array}{l}\text { Mean/Min/Max/SD PA: the average/smallest/largest/ standard deviation } \\
\text { of all patch areas of a particular land cover type. SD PA indicates the } \\
\text { level of deviation from the mean patch area for one particular land } \\
\text { cover type }\end{array}$ \\
\hline & Patch core area & $\mathrm{PCO}$ & $\begin{array}{l}\text { Mean/Min/Max/SD PCO: the average/smallest/largest/standard deviation } \\
\text { patch core area of a particular land cover type. SD PA indicates the } \\
\text { level of deviation from the mean patch core area for one particular land } \\
\text { cover type }\end{array}$ \\
\hline \multirow[t]{3}{*}{$\begin{array}{l}\text { Shape } \\
\text { complexity }\end{array}$} & $\begin{array}{l}\text { Perimeter area ratio of } \\
\text { each land cover type }\end{array}$ & PAR & $\begin{array}{l}\mathrm{PAR}=\frac{p_{j}}{a_{j}} \text {, where } p_{j} \text { is the perimeter of patch } j \text { and } a_{j} \text { is the area of patch } j . \\
\text { Mean/Min/Max/SD PAR: the average/smallest/largest/ standard } \\
\text { deviation perimeter area ratio for one particular land cover type. SD } \\
\text { PAR indicates the level of deviation from the mean perimeter area ratio } \\
\text { for one particular land cover type }\end{array}$ \\
\hline & $\begin{array}{l}\text { Landscape shape index } \\
\text { of land cover type }\end{array}$ & LSI & $\begin{array}{l}\text { LSI }=\frac{0.25 E}{\sqrt{A}} \text {, where } E \text { is the total edges of patches of one land cover type } \\
\text { and } A \text { is the total landscape area }\end{array}$ \\
\hline & $\begin{array}{l}\text { Shape index of each } \\
\text { patch }\end{array}$ & SI & $\begin{array}{l}\text { Mean/Min/Max/SD SI: the average/smallest/largest/standard deviation } \\
\text { shape index for one particular land cover type. SD SI indicates the level } \\
\text { of deviation from the mean value of the shape index for one particular } \\
\text { land cover type }\end{array}$ \\
\hline \multirow[t]{2}{*}{ Fragmentation } & $\begin{array}{l}\text { Patch density of each } \\
\text { land cover type }\end{array}$ & PD & $\begin{array}{l}\mathrm{PD}=\frac{N_{i}}{A} \text {, where } N_{i} \text { is the total number of patches for the particular land } \\
\text { cover type and } A \text { is the total landscape area }\end{array}$ \\
\hline & Splitting Index & SPI & $\begin{array}{l}\text { SPI }=\frac{A^{2}}{\sum_{i=1}^{m} \sum_{j=1}^{n} a_{i j}} \text {, aij is area of patch } i j, A \text { is total landscape area. The } \\
\text { degree of patch isolation for one particular land cover type }\end{array}$ \\
\hline Connectivity & Patch cohesion index & PCI & $\begin{array}{l}\mathrm{PCI}=1-\left(\sum_{j=1}^{m} p_{j} / \sum_{j=1}^{m} p_{j} \sqrt{a_{j}}\right)\left(1-\frac{1}{\sqrt{A}}\right)^{-1} \text {, where } m \text { is the number } \\
\text { of patches of each land cover type, } a_{j} \text { is the area of patch, } p_{j} \text { is the } \\
\text { perimeter of patch } j \text { and } A \text { is the total landscape area }\end{array}$ \\
\hline Diversity & $\begin{array}{l}\text { Landscape Shannon } \\
\text { diversity index }\end{array}$ & LSHD & $\begin{array}{l}\mathrm{LSHD}=-\sum_{i}^{n} P_{i} \ln P_{i} \text {, where } n \text { is the number of land cover types and } P i \\
\text { is the percentage of land cover } i\end{array}$ \\
\hline Contagion & Contagion index & CI & $\begin{array}{l}\left.\mathrm{CI}=\left[1+\frac{\sum_{i=1}^{m} \sum_{k=1}^{m}\left[\left(P_{i}\right)\left(\frac{g_{i k}}{\sum_{i=1}^{g_{i k}}}\right)\right]\left[\ln \left(P_{i}\right)\left(\frac{g_{i k}}{2 \ln (m)}\right)\right]}{\sum_{i=1}^{g_{i k}}}\right)\right] \text {, where } P_{i} \text { is the } \\
\text { percentage of patch type } i, g_{i k} \text { is the number of patch type } i \text {, and } m \text { is } \\
\text { the number of land cover types in a buffer. High CI indicates large and } \\
\text { well-connected patches }\end{array}$ \\
\hline Aggregation & Aggregation index & AI & $\begin{array}{l}\mathrm{AI}=\frac{g_{i i}}{\max \rightarrow g_{i i}}, g_{i i} \text { is the number of like adjacencies between pixels of } \\
\text { patch } i \text { based on the single-count method. } \max \rightarrow g_{i i} \text { is the maximum } \\
\text { number of like adjacencies between pixels of patch } i \text { based on the } \\
\text { single-count method. The value of AI ranges from } 0 \text { to } 1 \text {, and high AI } \\
\text { means more aggregated patches }\end{array}$ \\
\hline
\end{tabular}

The other model is the spatial error model (SEM) that estimates the spatial autocorrelation existing in the regression residuals of the neighboring location (i.e. the spatial error) of the OLS model, as given by Eq. (3):

$\mathrm{y}=\beta \mathrm{X}+\lambda \mathrm{W} \epsilon+\mu$ where $\lambda$ is the spatial autoregressive coefficient for the spatial error variable $\mathrm{W} \epsilon$ and $\mu$ is the random factor of disturbances.

We fitted in total seven models for the fine (two models) and the coarse (five models) scales. The performance of OLS and spatial auto-regression 
models were compared using Akaike Information Criterion (AIC). AIC, as a model selection criterion, has a sound likelihood framework, based on KullbackLeibler information loss between estimates of the model and actual values and allows the comparisons among models (Burnham and Anderson 2004). A lower AIC value means better fit of the model, thus the model with the lowest AIC value is deemed as the best model. Spatial regressions were carried out in GeoDa and the other analyses in R 3.3.3 software.

\section{Results}

Waterbird diversity of the survey sites in the Yangtze River Floodplain measured by the Shannon-Wiener index is shown in Table S1. The Shannon-Wiener index values varies between 0 and 2.6877 (mean = $1.32 \pm 0.69 \mathrm{SD}$ ). The highest waterbird diversity was found in the Poyang Lake Nature Reserve in Jiangxi Province, followed by Chen Lake and Liangzi Lake in Hubei province, while relatively lower ShannonWiener values occurred in Ge Lake in Jiangsu province, the Aquafarm of Jieshou Town in Anhui province and West Yangcheng Lake in Jiangsu province (Table S1).

At both fine and coarse scales, the p-value of $\lambda$ in SLM and that of $\rho$ in SEM were higher than 0.05, which indicated that no strong spatial autocorrelation was observed among survey sites. Thus, we retained OLS models to estimate the influence of landscape features on waterbird diversity (Table 2).

According to the coefficient of each significant metric (Table 2; Fig. 2), we found waterbird diversity was strongly associated with the surrounding landscape matrix at both fine and coarse scales, and the effect was stronger at the coarse scales. At fine scales, a higher waterbird diversity was associated with a lower connectivity of developed area (i.e., lower PCI, a negative effect). At coarse scales, developed area showed the most pronounced effect on waterbird diversity, i.e., habitats surrounded by developed area of regular shapes (i.e., higher LSI, a positive effect) tended to have a higher waterbird diversity (Fig. 2). In addition, regular-shaped croplands (i.e. higher LSI, Mean SI and SD SI; positive effects) and larger irregular-shaped forest patches (i.e. higher Min SI and Mean PCA; positive effects) facilitated a higher waterbird diversity.
Significant relationships between habitat features and waterbird diversity were found at both fine and coarse scales (Table 2). At fine scales, the important variables included patch density (PD) of grassland and SD shape index (SD SI) of shrub. Waterbird diversity was significantly higher in more connected grassland (i.e. lower PD, a negative effect) and more irregularshaped shrub (i.e. higher SD SI, a positive effect). At coarse scales, the important variables were the landscape shape index (LSI), the splitting index of shrub, the Mean shape index (Mean SI) and aggregation index (AI) of wetland. Irregular-shaped and wellconnected wetland (i.e. higher Mean SI and AI, a positive effect), as well as irregular-shaped shrub (i.e. higher LSI, a positive effect) contributed to a high waterbird diversity whereas the isolated shrub (i.e. higher SI, a negative effect) resulted in a low waterbird diversity.

\section{Discussion}

This study investigated the impact of habitat features and landscape matrices on waterbird diversity across spatial scales. At fine scales, well-connected habitats (grassland and shrub) surrounded by isolated and regular-shaped developed area helped maintain high waterbird diversity. At coarse scales, waterbird diversity was higher in areas where aggregated wetlands were surrounded by regular-shaped developed area and croplands, and large irregular-shaped forests. Developed areas consistently influenced waterbird diversity and showed the most pronounced effect at coarse scales. The landscape matrix in which wildlife habitat is embedded should be managed wherever possible (Prugh et al. 2008; Franklin and Lindenmayer 2009), especially when expanding the developed area.

Waterbird diversity was negatively correlated with fragmentated habitats (i.e., isolated grassland, regular and isolated shrub and unconnected wetland with regular boundaries). Well-connected grassland, shrub and wetland habitat provide important foraging and resting area for waterbirds (Stafford et al. 2009; Pearse et al. 2012). Connectivity, at both fine and coarse scales, is important for waterbird aggregation (Guadagnin and Maltchik 2007). At finer scales, wellconnected habitats facilitate the movement of waterbirds between feeding and roosting sites (Elphick 
Table 2 The influence of landscape features on waterbird diversity in the Yangtze River Floodplain at fine and coarse scales

\begin{tabular}{|c|c|c|c|c|c|c|}
\hline \multirow[t]{2}{*}{ Scale } & \multirow[t]{2}{*}{ Buffer } & \multirow{2}{*}{$\begin{array}{l}\text { Model } \\
\text { Independent variable }\end{array}$} & \multicolumn{4}{|c|}{ Dependent variable: Shannon-Winner index of waterbirds } \\
\hline & & & Coefficient & P-value & Adjust $\mathrm{R}^{2}$ (OLS) & AIC (OLS) \\
\hline \multirow[t]{4}{*}{ Fine scale } & $5 \mathrm{~km}$ & - the PCI of developed area & -0.490 & $0.024 *$ & 0.283 & 82.081 \\
\hline & & - the PD of grassland & -0.350 & $0.001 * *$ & & \\
\hline & $10 \mathrm{~km}$ & - the SD SI of developed area & -1.126 & $0.042^{*}$ & 0.514 & 30.311 \\
\hline & & + the SD SI of shrub & 3.179 & $0.003 * *$ & & \\
\hline \multirow[t]{11}{*}{ Coarse scale } & $15 \mathrm{~km}$ & + the LSI of shrub & 0.053 & $0.013 *$ & 0.303 & 51.813 \\
\hline & & - the LSI of cropland & -0.004 & $0.008 * *$ & & \\
\hline & $20 \mathrm{~km}$ & - the Mean SI of cropland & -2.260 & $0.031 *$ & 0.233 & 77.635 \\
\hline & & + the Mean SI of wetland & 1.442 & $0.005 * *$ & & \\
\hline & $30 \mathrm{~km}$ & - the SD SI of cropland & -0.810 & $0.029 *$ & 0.139 & 99.897 \\
\hline & & + the AI of wetland & 0.106 & $0.031 *$ & & \\
\hline & $40 \mathrm{~km}$ & - the Mean SI of developed area & -4.458 & $0.001 * *$ & 0.235 & 97.674 \\
\hline & & + the Mean PCA of forest & $1.567 \mathrm{e}-6$ & $0.012 *$ & & \\
\hline & & + the Min SI of forest & 2.733 & $0.013^{*}$ & & \\
\hline & $50 \mathrm{~km}$ & - the Mean SI of developed area & -2.887 & $0.015^{*}$ & 0.160 & 100.302 \\
\hline & & - the SPI of shrub & $-1.123 \mathrm{e}-4$ & $0.027 *$ & & \\
\hline
\end{tabular}

'+' means positive effects while '-' means negative effects

The credible interval of the estimate is $95 \%$. $* \mathrm{P}<0.05$ (two-sided test), $* * \mathrm{P}<0.01$ (two-sided test), $* * * \mathrm{P}<0.001$ (two-sided test) Landscape metrics: PCI patch cohesion index, PD patch density, SD SI standard deviation of shape index, LSI landscape shape index, Mean SI mean shape index, AI aggregation index, Mean PCA mean patch core area, Min SI minimum shape index, SPI splitting index

2008), which can reduce the costs due to shorter foraging flight distances. In addition, we found that waterbird diversity was lower in sites with regularshaped shrub and wetland patches at coarser scales. In general, the regular and less complex patches are often associated with intensive human influnce (Mcgarigal and Marks 1995; Cunningham and Johnson 2011), whereas less disturbed patches are more complex (Krauss and Klein 2004). Furthermore, habitat patches with a higher shape complexity tended to have increased foraging resources (Andrade et al. 2018). Therefore, irregular-shaped shrub and wetland habitat helped to maintain a higher waterbird diversity due to the lower level of human disturbance and the higher level of potential food resources.

Developed area was the most critical factor influencing waterbird diversity, particularly at coarse scales. Though a previous study found that the presence of developed area negatively influenced waterbird richness (Rosa et al. 2003), we suggest that habitat surrounded by isolated or regular-shaped developed area can help to maintain higher waterbird diversity. Isolated developed area indicated a lower level of connectivity of surrounding patches, resulting in a higher connectivity of waterbird habitat patches (Pearce et al. 2007; Larsonab and Perrings 2013). In other words, well-connected surrounding landscape patches (i.e. developed area) indicated higher habitat degradation and fragmentation, which leads to a lower waterbird diversity. In particular, the effect of shape complexity of developed area was more prominent. Waterbird diversity decreased as the shape complexity of surrounding developed area increased. Surrounding developed patches with a more complex shape tended to have a longer border with the adjacent natural habitats, indicating a higher level of human disturbance (Gyenizse et al. 2014). Regular-shaped developed patches resulted in less disturbance to the habitat and hence support higher waterbird diversity.

Other landscape matrices, such as cropland and forest, also affected waterbird diversity. Regularshaped cropland and larger irregular-shaped forest tended to facilitate a higher waterbird diversity. Similar to the developed area, regular-shaped cropland 


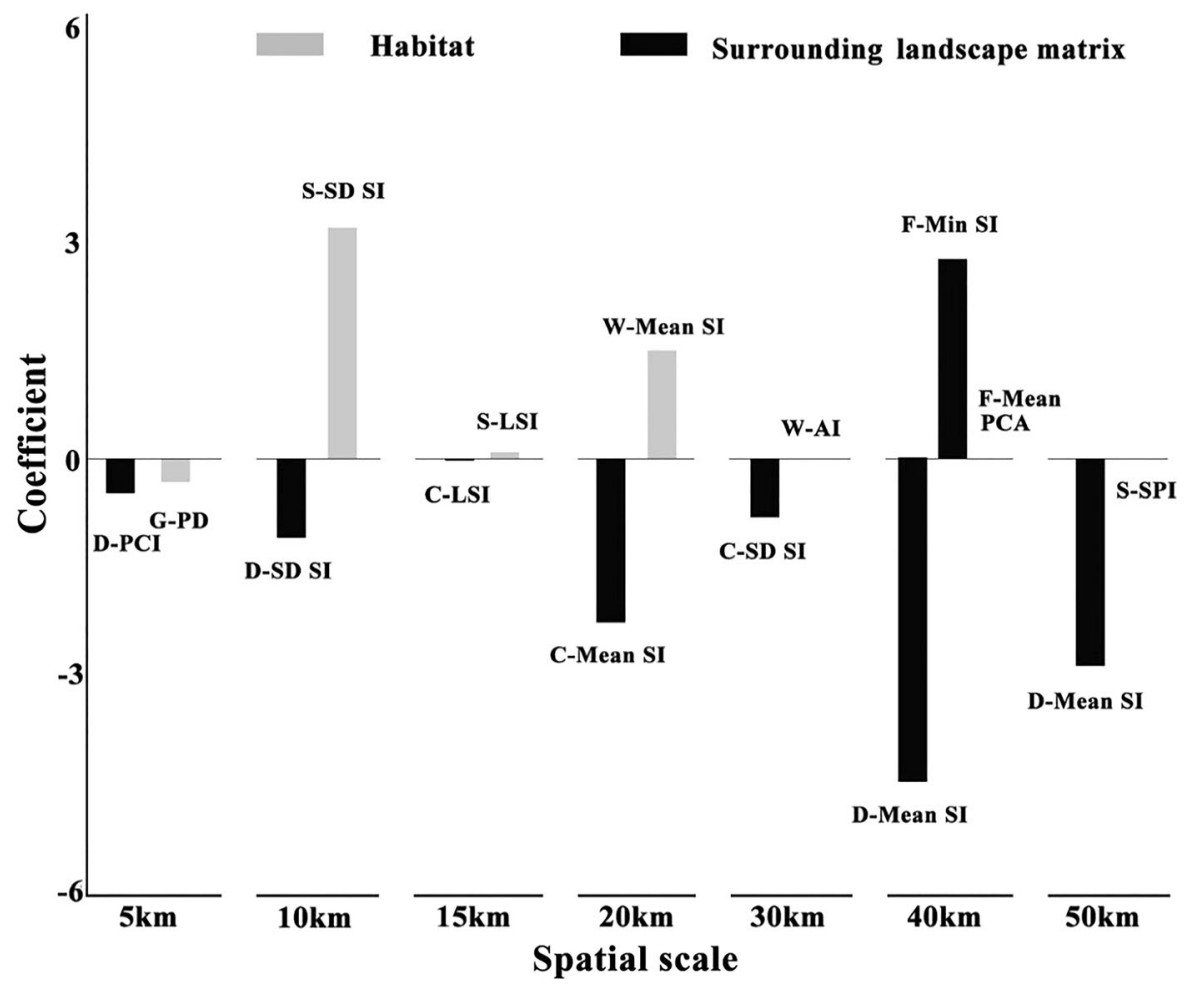

Fig. 2 Effects of landscape features on waterbird diversity along Yangtze River Floodplain. Black bars denote landscape matrices and grey bars denote habitat. The length of the bar depicts the coefficient of each metric representing the level of importance. Landscape metrics that have statistically significant values are displayed: D-PCI indicates the patch cohesion index (PCI) of developed area (D); G-PD means the patch density (PD) of grassland $(\mathrm{G})$; D-SD SI indicates the standard deviation of shape index (SD SI) of developed area; S-SD SI means the SD SI of shrub (S); C-LSI indicates the landscape shape index (LSI)

indicated a lower level of habitat invasion and disturbance. Habitats surrounded by natural land tended to support more species due to relatively low human disturbance (Vandermeer and Carvajal 2001). Larger irregular-shaped forest patches could act as a buffer insulating core habitats from intensive human activities such as urban-rural development and agriculture expansion (Findlay and Houlahan 1997) thus facilitating a higher waterbird diversity.

We found that both habitat features and surrounding landscape matrices influenced waterbird diversity at fine scales, whereas at coarse scales the effect of the landscape matrix outweighed that of the habitat. At fine scales, waterbird diversity was facilitated by wellconnected habitats surrounded by regular-shaped developed area. Whereas at coarse scales, the of cropland (C); S-LSI means the LSI of shrub; C-Mean SI indicates the mean shape index (Mean SI) of cropland; W-Mean SI means the Mean SI of wetland (W); C-SD SI indicates the SD SI of cropland; W-AI means the aggregation index (AI) of wetland; D-Mean SI indicates the Mean SI of developed area; F-Min SI means the minimum shape index (Min SI) of forest (F); F-Mean PCA means the mean patch core area (Mean PCA) of forest; D-Mean SI indicates the Mean SI of developed area; S-SPI means the splitting index (SPI) of shrub

surrounding matrices (with the shape of developed area outperformed others) played the most important role in determining species diversity. The reason might be that initial habitat selection is mainly based on the appearance of the landscape (Moore and Aborn 2000), and birds tend to avoid regions with the habitat surrounded by well-connected landscape matrices. This kind of landscape tends to have more fragmented habitat patches and a relatively higher human disturbance. Among different types of landscape matrices, developed area had the most pronounced negative effect on waterbird diversity, probably because the level of human activity intensity is the highest in the developed area in comparison to other landscape matrices. We acknowledge that imperfect detection during surveys might negatively impact data quality 
(false absences or false presence of species) and interpretation. We suggest increasing the number of surveys for each location in the future to further validate our findings.

\section{Conclusion}

Habitat features and landscape matrices jointly affected waterbird diversity, and the effect of the landscape matrix was more pronounced at coarse scales. Well-connected habitats (e.g. wetland, shrub and grassland) surrounded by isolated regular-shaped developed area and cropland, and large irregularshaped forest helped maintain a higher waterbird diversity. Regular-shaped developed area was a critical factor that consistently facilitates a higher waterbird diversity across scales. Wetland managers should maintain well-connected habitats (wetland, grassland and shrub), and urban and rural landscape planners should minimize the expansion of developed areas to critical habitats and leave sufficient buffer to maintain the habitat connectivity and shape complexity in order to reduce the disturbance to birds. Our findings provide insights into understanding how waterbirds respond to altered landscapes and offer practical measures to help mitigate the human-bird conflicts in biodiversity hotspot areas.

Acknowledgements This research was supported by the National Research Program of the Ministry of Science and Technology of the People's Republic of China (No. 2017YFA0604404), the National Natural Science Foundation of China (No. 41471347), donations from Delos Living LLC and the Cyrus Tang Foundation to Tsinghua University, and the China Scholarship Council (201806210038). We thank the World Wide Fund for Nature (WWF) for providing bird observation data, and Y. Zheng for providing the boundary of the Yangtze River basins.

Open Access This article is licensed under a Creative Commons Attribution 4.0 International License, which permits use, sharing, adaptation, distribution and reproduction in any medium or format, as long as you give appropriate credit to the original author(s) and the source, provide a link to the Creative Commons licence, and indicate if changes were made. The images or other third party material in this article are included in the article's Creative Commons licence, unless indicated otherwise in a credit line to the material. If material is not included in the article's Creative Commons licence and your intended use is not permitted by statutory regulation or exceeds the permitted use, you will need to obtain permission directly from the copyright holder. To view a copy of this licence, visit http://creativecommons.org/licenses/by/4.0/.

\section{References}

Ackerman JT, Takekawa JY, Orthmeyer DL, Fleskes JP, Yee JL, Kruse KL (2006) Spatial use by wintering greater whitefronted geese relative to a decade of habitat change in California's Central Valley. J Wildl Manag 70(4):965-976

Amano T, Székely T, Sandel B, Nagy S, Mundkur T, Langendoen T, Blanco D, Soykan CU, Sutherland WJ (2018) Successful conservation of global waterbird populations depends on effective governance. Nature 553(7687):199-202

Andrade R, Bateman HL, Franklin J, Allen D (2018) Waterbird community composition, abundance, and diversity along an urban gradient. Landsc Urban Plan 170:103-111

Bailey D, Billeter R, Aviron S, Schweiger O, Herzog F (2007) The influence of thematic resolution on metric selection for biodiversity monitoring in agricultural landscapes. Landsc Ecol 22(3):461-473

Beatty WS, Webb EB, Kesler DC, Raedeke AH, Naylor LW, Humburg DD (2014) Landscape effects on mallard habitat selection at multiple spatial scales during the non-breeding period. Landsc Ecol 29(6):989-1000

Burnham KP, Anderson DR (2004) Multimodel inference understanding AIC and BIC in model selection. Sociol Methods 33(2):261-304

Chan S-F, Severinghaus LL, Lee C-K (2007) The effect of rice field fragmentation on wintering waterbirds at the landscape level. J Ornithol 148(2):333-342

Concepcion ED, Obrist MK, Moretti M, Altermatt F, Baur B, Nobis MP (2016) Impacts of urban sprawl on species richness of plants, butterflies, gastropods and birds: not only built-up area matters. Urban Ecosyst 19(1):225-242

Cunningham MA, Johnson DH (2011) Seeking parsimony in landscape metrics. J Wildl Manag 75(3):692-701

Dallimer M, Marini L, Skinner AMJ, Hanley N, Armsworth PR, Gaston KJ (2010) Agricultural land-use in the surrounding landscape affects moorland bird diversity. Agric Ecosyst Environ 139(4):578-583

De Camargo RX, Boucher-Lalonde V, Currie DJ (2018) At the landscape level, birds respond strongly to habitat amount but weakly to fragmentation. Divers Distrib 24(5):629-639

De Smith MJ, Goodchild MF, Longley P (2007) Geospatial analysis: a comprehensive guide to principles, techniques and software tools. Troubador Publishing Ltd, Kibworth

Debinski DM, Ray C, Saveraid EH (2001) Species diversity and the scale of the landscape mosaic: do scales of movement and patch size affect diversity? Biol Conserv 98(2):179-190

Dronova I, Beissinger S, Burnham J, Gong P (2016) Landscapelevel associations of wintering waterbird diversity and abundance from remotely sensed wetland characteristics of Poyang Lake. Remote Sens 8(6):22

Dudgeon D, Arthington AH, Gessner MO, Kawabata Z-I, Knowler DJ, Lévêque C, Naiman RJ, Prieur-Richard A-H, Soto D, Stiassny MLJ, Sullivan CA (2006) Freshwater biodiversity: importance, threats, status and conservation challenges. Biological Reviews 81(2):163-182

Egerer MH, Bichier P, Philpott SM (2016) Landscape and local habitat correlates of lady beetle abundance and species richness in urban agriculture. Ann Entomol Soc Am 110(1):97-103

Elphick CS (2008) Landscape effects on waterbird densities in California rice fields: taxonomic differences, scale- 
dependence, and conservation implications. Waterbirds 31(1):62-69

Findlay CS, Houlahan J (1997) Anthropogenic correlates of species richness in Southeastern Ontario wetlands. Conserv Biol 11(4):1000-1009

Fischer J, Lindenmayer DB (2007) Landscape modification and habitat fragmentation: a synthesis. Glob Ecol Biogeogr 16(3):265-280

Flather C, Sauer J (1996) Using landscape ecology to test hypotheses about large scale abundance patterns in migratory birds. Ecology 77:28-35

Forbes S (2000) Wetland birds. Habitat resources and conservation Implications. Auk 117(3):844-845

Forcey GM, Thogmartin WE, Linz GM, Bleier WJ, McKann PC (2011) Land use and climate influences on waterbirds in the Prairie Potholes. J Biogeogr 38(9):1694-1707

Francesiaz C, Guilbault E, Lebreton J-D, Trouvilliez J, Besnard A (2017) Colony persistence in waterbirds is constrained by pond quality and land use. Freshw Biol 62(1):119-132

Franklin JF, Lindenmayer DB (2009) Importance of matrix habitats in maintaining biological diversity. Proc Natl Acad Sci 106(2):349

Galewski T, Collen B, McRae L, Loh J, Grillas P, GauthierClerc M, Devictor V (2011) Long-term trends in the abundance of Mediterranean wetland vertebrates: from global recovery to localized declines. Biol Conserv 144

García-Llamas P, Calvo L, De La Cruz M, Suárez-Seoane S (2018) Landscape heterogeneity as a surrogate of biodiversity in mountain systems: what is the most appropriate spatial analytical unit? Ecol Indic 85:285-294

Green AJ (1996) Analyses of globally threatened Anatidae in relation to threats, distribution, migration patterns, and habitat use. Conserv Biol 10:1435-1445

Green AJ, Alcorlo P, Peeters ETHM, Morris EP, Espinar JL, BravoUtrera MA, Bustamante J, Díaz-Delgado R, Koelmans AA, Mateo R, Mooij WM, Rodríguez-Rodríguez M, van Nes EH, Scheffer M (2017) Creating a safe operating space for wetlands in a changing climate. Front Ecol Environ 15(2):99-107

Guadagnin DL, Maltchik L (2007) Habitat and landscape factors associated with neotropical waterbird occurrence and richness in wetland fragments. Biodivers Conserv 16(4):1231-1244

Guadagnin DL, Maltchik L, Fonseca CR (2009) Species-area relationship of Neotropical waterbird assemblages in remnant wetlands: looking at the mechanisms. Divers Distrib 15(2):319-327

Gyenizse P, Bognár Z, Czigány S, Elekes T (2014) Landscape shape index, as a potential indicator of urban development in Hungary. Landsc Environ 8:78-88

Herbert JA, Chakraborty A, Naylor LW, Beatty WS, Krementz DG (2018) Effects of landscape structure and temporal habitat dynamics on wintering mallard abundance. Landsc Ecol 33(8):1319-1334

Hill MO (1973) Diversity and evenness: a unifying notation and its consequences. Ecology 54(2):427-432

Hollert H (2013) Processes and environmental quality in the Yangtze River system. Environ Sci Pollut Res 20(10):6904-6906

Honnay O, Piessens K, Van Landuyt W, Hermy M, Gulinck H (2003) Satellite based land use and landscape complexity indices as predictors for regional plant species diversity. Landsc Urban Plan 63(4):241-250
Johnson WP, Schmidt PM, Taylor DP (2014) Foraging flight distances of wintering ducks and geese: a review. Avian Conserv Ecol 9(2)

Krauss J, Klein AM (2004) Effects of habitat area, isolation, and landscape diversity on plant species richness of calcareous grasslands. Biodivers Conserv 13(8):1427-1439

Larsonab EK, Perrings C (2013) The value of water-related amenities in an arid city: the case of the Phoenix metropolitan area. Landsc Urban Plan 109(1):45-55

Lausch A, Herzog F (2002) Applicability of landscape metrics for the monitoring of landscape change: issues of scale, resolution and interpretability. Ecol Indic 2(1-2):3-15

Li H, Reynolds JF (1993) A new contagion index to quantify spatial patterns of landscapes. Landsc Ecol 8(3):155-162

Li C, Gong P, Wang J, Yuan C, Hu T, Wang Q, Yu L, Clinton N, Li M, Guo J, Feng D, Huang C, Zhan Z, Wang X, Xu B, Nie Y, Hackman K (2016) An all-season sample database for improving land-cover mapping of Africa with two classification schemes. Int J Remote Sens 37(19):4623-4647

Li X, Si Y, Ji L, Gong P (2017) Dynamic response of East Asian Greater White-fronted Geese to changes of environment during migration: use of multi-temporal species distribution model. Ecol Modell 360:70-79

Lin Y, Chang C, Chu H, Cheng B (2011) Identifying the spatial mixture distribution of bird diversity across urban and suburban areas in the metropolis: a case study in Taipei Basin of Taiwan. Landsc Urban Plan 102(3):156-163

Macarthur R (1955) Fluctuations of animal populations and a measure of community stability. Ecology 36(3):533-536

Madsen J (1985) Relations between change in spring habitat selection and daily energetics of Pink-Footed Geese Anser brachyrhynchus. Ornis Scand 16(3)

Marquardt DW (1970) Generalized inverses, ridge regression, biased linear estimation, and nonlinear estimation. Technometrics 12(3):591-612

Martínez-Abraín A, Oro D, Gómez J, Pérez J (2016) Differential waterbird population dynamics after long-term protection: the influence of food and habitat type. Ardeola 63(1)

Mcalpine CA, Eyre TJ (2002) Testing landscape metrics as indicators of habitat loss and fragmentation in continuous eucalypt forests (Queensland, Australia). Landsc Ecol 17(8):711-728

Mcgarigal K, Marks BJ (1995) FRAGSTATS: spatial pattern analysis program for quantifying landscape structure. General Technical Report Pnw 351

Moore F, Aborn D (2000) Mechanisms of en route habitat selection: how do migrants make habitat decisions during stopover? Avian Biol 20

Morelli F, Pruscini F, Santolini R, Perna P, Benedetti Y, Sisti D (2013) Landscape heterogeneity metrics as indicators of bird diversity: determining the optimal spatial scales in different landscapes. Ecol Indic 34:372-379

Morimoto T, Katoh K, Yamaura Y, Watanabe S (2006) Can surrounding land cover influence the avifauna in urban/suburban woodlands in Japan? Landsc Urban Plan 75:143-154

Nassauer JI (2004) Monitoring the success of metropolitan wetland restorations: cultural sustainability and ecological function. Wetlands 24(4):756-765

Nilsson C, Reidy CA, Dynesius M, Revenga C (2005) Fragmentation and flow regulation of the world's large river systems. Science 308(5720):405-408 
Niu Z, Zhang H, Wang X, Yao W, Zhou D, Zhao K, Zhao H, Li N, Huang H, Li C (2012) Mapping wetland changes in China between 1978 and 2008. Chin Sci Bull 57:2813-2823

Ogden JC, Baldwin JD, Bass OL, Browder JA, Cook MI, Frederick PC, Frezza PE, Galvez RA, Hodgson AB, Meyer KD (2014) Waterbirds as indicators of ecosystem health in the coastal marine habitats of southern Florida: 1. Selection and justification for a suite of indicator species. Ecol Indic 44(9):148-163

Olson DM, Dinerstein E (2002) The Global 200: priority ecoregions for global conservation. Ann Mo Bot Gard 89(2):199-224

Olson DM, Dinerstein E, Poker J, Stein I, Werder U (1998) The Global 200: a representation approach to conserving the earth's most biologically valuable ecoregions. Conserv Biol 12(3):502-515

Paracuellos M, Telleria JL (2004) Factors affecting the distribution of a waterbird community: the role of habitat configuration and bird abundance. Waterbirds 27(4):446-453

Payne LX, Schindler DE, Parrish JK, Temple SA (2005) Quantifying spatial pattern with evenness indices. Ecol Appl 15(2):507-520

Pearce CM, Green MB, Baldwin MR (2007) Developing habitat models for waterbirds in urban wetlands: a log-linear approach. Urban Ecosyst 10(3):239-254

Pearse AT, Kaminski RM, Reinecke KJ, Dinsmore SJ (2012) Local and landscape associations between wintering Dabbling Ducks and wetland complexes in Mississippi. Wetlands 32(5):859-869

Perez-Garcia JM, Sebastian-Gonzalez E, Alexander KL, Sanchez-Zapata JA, Botella F (2014) Effect of landscape configuration and habitat quality on the community structure of waterbirds using a man-made habitat. Eur J Wildl Res 60(6):875-883

Prugh LR, Hodges KE, Sinclair ARE, Brashares JS (2008) Effect of habitat area and isolation on fragmented animal populations. Proc Natl Acad Sci 105(52):20770

Ricotta C, Corona P, Marchetti M, Chirici G, Innamorati S (2003) LaDy: software for assessing local landscape diversity profiles of raster land cover maps using geographic windows. Environ Model Softw 18(4):373-378

Riitters KH, O'neill R, Hunsaker C, Wickham JD, Yankee D, Timmins S, Jones K, Jackson B (1995) A factor analysis of landscape pattern and structure metrics. Landsc Ecol 10(1):23-39

Rosa S, Palmeirim JM, Moreira F (2003) Factors affecting waterbird abundance and species richness in an increasingly urbanized area of the Tagus Estuary in Portugal. Waterbirds 26(2):226

Saab V (1999) Importance of spatial scale to habitat use by breeding birds in riparian forests: a hierarchical analysis. Ecol Appl 9:135-151

Si Y, Skidmore AK, Wang T, de Boer WF, Toxopeus AG, Schlerf M, Oudshoorn M, Zwerver S, Hvd Jeugd, Exo K-M, Prins HHT (2011) Distribution of barnacle GeeseBranta leucopsisin relation to food resources, distance to roosts, and the location of refuges. Ardea 99(2):217-226

Si Y, Wei J, Wu W, Zhang W, Hou L, Yu L, Wielstra B (2020) Reducing human pressure on farmland could rescue China's declining wintering geese. Movement Ecology 8:35

Simmonds JS, Rensburg BJ, Tulloch AIT, Maron M (2019) Landscape-specific thresholds in the relationship between species richness and natural land cover. J Appl Ecol 56(4):1019-1029

Šímová P, Gdulová K (2012) Landscape indices behavior: a review of scale effects. Appl Geogr 34:385-394

Sklenicka P, Janovska V, Salek M, Vlasak J, Molnarova K (2014) The Farmland Rental Paradox: extreme land ownership fragmentation as a new form of land degradation. Land Use Policy 38:587-593

Souza FL, Valente-Neto F, Severo-Neto F, Bueno B, OchoaQuintero JM, Laps RR, Bolzan F, Roque FD (2019) Impervious surface and heterogeneity are opposite drivers to maintain bird richness in a Cerrado city. Landsc Urban Plan 192:10

Stafford J, Horath M, Yetter A, Hine C, Havera S (2009) Wetland use by Mallards during spring and fall in the Illinois and Central Mississippi River Valleys. Waterbirds 30:394-402

Summers PD, Cunnington GM, Fahrig L (2011) Are the negative effects of roads on breeding birds caused by traffic noise? J Appl Ecol 48(6):1527-1534

Vandermeer J, Carvajal R (2001) Metapopulation dynamics and the quality of the matrix. Am Nat 158(3):211-220

Walz U (2011) Landscape structure, landscape metrics and biodiversity. Living Rev Landsc Res 5(3):1-35

Wang JW, Poh CH, Tan CYT, Lee VN, Jain A, Webb EL (2017) Building biodiversity: drivers of bird and butterfly diversity on tropical urban roof gardens. Ecosphere 8(9):22

Webb EB, Smith LM, Vrtiska MP, Lagrange TG (2010) Effects of local and landscape variables on wetland bird habitat use during migration through the rainwater basin. J Wildl Manag 74(1):109-119

Wei J, Xin Q, Ji L, Gong P, Si Y (2019) A new satellite-based indicator to identify spatiotemporal foraging areas for herbivorous waterfowl. Ecol Indic 99:83-90

Wiens JA (1989) Spatial scaling in ecology. Funct Ecol 3(4):385-397

Wu CF, Lin YP, Lin SH (2011) A hybrid scheme for comparing the effects of bird diversity conservation approaches on landscape patterns and biodiversity in the Shangan subwatershed in Taiwan. J Environ Manag 92(7):1809-1820

Xie C, Huang X, Mu H, Yin W (2017) Impacts of land-use changes on the lakes across the Yangtze Floodplain in China. Environ Sci Technol 51(7):3669-3677

Xu F, Liu G, Si Y (2017) Local temperature and El Nino Southern Oscillation influence migration phenology of East Asian migratory waterbirds wintering in Poyang, China. Integr Zool 12(4):303-317

Yu L, Wang J, Li X, Li C, Zhao Y, Gong P (2014) A multiresolution global land cover dataset through multisource data aggregation. Sci China Earth Sci 57(10):2317-2329

Yu L, Li X, Li C, Zhao Y, Niu Z, Huang H, Wang J, Cheng Y, Lu H, Si Y, Yu C, Fu H, Gong P (2016) Using a global reference sample set and a cropland map for area estimation in China. Sci China Earth Sci 60(2):277-285

Zhang W, Li X, Yu L, Si Y (2018) Multi-scale habitat selection by two declining East Asian waterfowl species at their core spring stopover area. Ecol Indic 87:127-135

Publisher's Note Springer Nature remains neutral with regard to jurisdictional claims in published maps and institutional affiliations. 